\title{
DE BOVENWINDSCHE EILANDEN DER KOLONIE CURAÇAO,
}

DOOR

A. B. J. PRAKKEN.

Administrateur van Financiën der Kolonie Curaçao.

't Was zeker een daad van wijs beleid van den Gouverneur Helfrich om zoo spoedig mogelijk na het aanvaarden van zijn bestuur een bezoek te brengen aan de Bovenwindsche eilanden. Was het bezoek aan die eilanden reeds enkele malen door allerlei omstandigheden uitgesteld, den 5 den December bracht Hr. Ms. Zeeland den Gouverneur met zijn uitgebreid gevolg, bestaande uit de meeste departements chefs, op de reede van Sint Martin.

In meer dan 40 jaar was het eiland slechts Io maal door zijn Gouverneur bezocht, waarvan door Gouverneur de Jong van Beek en Donk, in zijn 9jarig bestuur, 6 maal met een oorlogschip.

Hoe zou de ontvangt zijn? We waren door lezing van een op Sint Martin verschijnend weekblad, getiteld Saint Martin, Day by Day, bekend geworden met een krachtige actie op dit eiland voor afscheiding van Curaçao en voor rechtstreeksch bestuur onder Nederland. De heer Waymouth, redacteur-uitgever van bovengenoemd blaadje, was een van de leiders der beweging en bij de laatste verkiezing was hij tot landraad gekozen met 37 stemmen tegen 30 stemmen op den heer Netherwood, die door den correspondent van het op Curaçao verschijnend blad De Vrijmoedige de candidaat van den handelsstand genoemd werd, terwijl de eerste als de candidaat van het volk werd beschouwd.

's Morgens vroeg lagen we met onzen oorlogsbodem voor de reede. Een prachtig gezicht bood het eiland aan. De geheel groene heuvels waren voor ons oog, dat door de langdurige droogte op Curaçao aan kale rotsen gewend geraakt was, een ware streeling. Wat leek ons Sint Martin een mooi en vruchtbaar bergland.

De gezaghebber der drie Bovenwindsche eilanden kwam den Gouverneur al spoedig begroeten en het duurde niet lang of de 
Marinesloep bracht ons, onder het bulderen van het kanon (de dertien saluutschoten voor den Gouverneur) naar het kleine houten steigertje, waar we door een commissie, waartoe, behalve de beide landraden, de heeren Waymouth en Richardson, o. a. behoorde de sedert kort aangekomen rechter Mr.Schagen van Leeuwen, die opgetreden is in verband met de nieuw ingevoerde rechtspraak.

Een hoerageroep, een bloemenhulde voor den Gouverneur, en vóór we het wisten liepen we door Philipsburg.

Wat een ontgoocheling. Dat in de verte zoo welvarend uitziend dorp bleek te zijn een vervallen en verwaarloosd plaatsje met nog geen I50o inwoners. De huizen waren verfloos, de galerijen stonden op instorten en de Gouvernementsgebouwen maakten hierop geen uitzondering. Het huis van den Gezaghebber was alleen met de komst van den tegenwoordigen titularis in het voorjaar opgeknapt. Verder was alles even slecht onderhouden en wees het op een vroegeren bloei, die reeds jaren en jaren aan het minderen was.

De bevolking, die zoo goed als uitsluitend Engelsch spreekt, is slechts voor een zeer klein deel het Nederlandsch machtig. De blanken behooren op Sint Martin niet uitsluitend tot de beter gesitueerden, zooals vrijwel algemeen op de Benedenwindsche eilanden het geval is, maar vele behooren tot de allerarmsten. Groot is ook het aantal gekleurden. De arbeiders trekken geregeld naar Santo Domingo en de Vereenigde Staten van Amerika, waar zij tegen hoog loon werk vinden. De mannen laten hun gezin, wanneer zij naar Santo Domingo trekken, meestal achter en komen elk jaar eenige maanden terug. Geheele gezinnen vertrekken naar de Vereenigde Staten om nooit terug te keeren, welke trek voortdurend toeneemit, en medewerkt het gebrek aan arbeiders te verhoogen.

Het arbeidersvraagstuk dat voor geheel Nederlandsch WestIndië onoplosbaar lijkt, is voor de Bovenwindsche eilanden ook van groot belang. Het klimaat van Sint Martin is voor den landbouw veel geschikter dan dat van Curaçao, al is de regenval ook daar vaak ongeregeld en doen zich ook daar lange perioden van droogte voor, maar het groote gebrek aan geschikte arbeidskrachten heeft de meeste plantages tot verval gebracht en het zal moeilijk zijn ze weer op te heffen. De plantagehouders kun- 
nen onmogelijk de hooge loonen geven, die in het buitenland betaald worden; daarvoor brengen de plantages te weinig op, waar één van de voornaamste cultures n. 1. de katoen, door den ongeregelden regenval te onzeker is. Deze cultuur was, dank zij de abnormaal hooge prijzen in de laatste jaren nog loonend, maar zal bij een dalende markt en riskante oogsten zeker niet behoorlijk rendeeren. Sommige plantagehouders verwachten heil van de suikercultuur, die in den slaventijd van groot belang was, maar thans is verdwenen. Ik meen echter dat hiervan weinig is te verwachten, omdat de regenval te wisselvallig is en deze cultuur op Cuba en in andere streken reeds zoo intensief plaats heeft, dat concurrentie vrijwel onmogelijk is. Hierbij komt nog, dat bij intensieven landbouw groot kapitaal noodzakelijk is en dit ontbreekt op Sint Martin geheel, en zal, in verband met het groote risico, moeilijk te krijgen zijn...

De grootlandbouwers zijn niet kapitaalkrachtig en zij behartigen, hoewel vaak nauw door familiebanden verbonden, weinig gezamenlijk hunne belangen. Door de handen in één te slaan kan misschien iets tot stand gebracht worden, speciaal op het gebied van veeteelt, muilezelfokkerij en de limoencultuur. Deze laatste cultuur heeft reeds getoond daar levensvatbaarheid te hebben niet alleen, maar de limoenen zijn bijzonder sappig, en in Engeland is voortdurend voor het geconcentreerde sap voldoende afzetgebied. Hierbij komt nog, dat de limoenstruiken weinig onderhoud eischen. Verder zou in het algemeen de vruchtencultuur kunnen worden uitgebreid, terwijl misschien proeven met ananas succes kunnen hebben. Een en ander zal door den aan te stellen hulplandbouwkundige, die op de onlangs door het Gouvernement gekochte uitgestrekte plantage Belvedère prachtige proefvelden verkrijgt, onderzocht kunnen worden, en wellicht vindt zijn voorbeeld navolging.

Van de kleinlandbouwers verwacht ik niet veel. De arbeider krijgt in loondienst, vooral als hij naar Santo Domingo trekt, een betere betaling, terwijl hij, waar hij over geen kapitaal beschikt, geen uithoudingsvermogen heeft om den tijd van het oogsten af te wachten.

Een van de voornaamste bronnen van inkomsten van Sint Martin was van oudsher de zoutwinning. Het groote zoutmeer direct achter de Backstreet in Philipsburg gelegen, geeft nog vele menschen brood, hoewel ook hier de concessionnarissen moeite 
hebben met het krijgen van arbeidskrachten voor het zoutgaren.

Een uitvoerig rapport omtrent de wijze van verbetering van de zoutpannen wordt opgemaakt door den ingenieur Langemeyer, die tevens op Sint Martin het havenvraagstuk bestudeert. Ik meen dan ook goed te doen niet op dit rapport, dat waarschijnlijk geplubiceerd zal worden, vooruit te loopen en te volstaan met de volgende opmerkingen.

De groote vraag is in deze het hebben van een afzetgebied. Dit lijkt moeilijk.

Hierbij spelen de hooge vrachtprijzen thans een belangrijke rol. Zout kan natuurlijk alleen als goedkoope retourvracht genomen worden, terwijl er niet veel kans bestaat voor de schepen om te Sint Martin of in de nabijheid, behoorlijke heenvracht te verkrijgen.

Daarbij komt nog, dat de middelen van transport voor zout op Sint Martin zeer gebrekkig zijn. Van de zouthoopen wordt het zout eerst in zakjes door vrouwen en kinderen naar den steiger gebracht en daar in de kleine bootjes geladen, die weder het zout naar de verder gelegen schoeners brengen.

Dit inladen eischt dus veel tijd en brengt groot oponthoud der schepen mede.

Wat het havenvraagstuk betreft, ook hier acht ik het wenschelijk het Regeeringsrapport af te wachten. Het ver van den steiger liggen van betrekkelijk kleine schoeners en de rotsachtige kust doen mij veronderstellen, dat het inrichten van een groote haven niet dan met zeer groote financieele offers gepaard zal gaan. Of, wanneer de Great Bay werkelijk een haven is, hiervan gebruik gemaakt zal worden, acht ik zeer twijfelachtig. De betrekkelijk dicht bij gelegen haven Sint Thomas heeft eenmaal het verkzer tot zich getrokken en het valt altijd zeer moeilijk de schepen van haven te doen veranderen, temeer waar Sint Martin geen achterland heeft en dus voornamelijk als doorvoerhaven en kolenstation dienst zou moeten doen. Voegt men hierbij het gebrek aan arbeidskrachten op Sint Martin dan lijkt mij de toestand alles behalve gunstig, temeer waar de vloot die de Amerikaansche haven Sint Thomas aandoet voornamelijk uit Amerikaansche schepen bestaat.

Wat de muntkwestie betreft het volgende. Behalve het gewone Curaçaosche geld was vroeger in omloop het Fransche geld, afkomstig van het Fransch gedeelte van Sint Martin en het 
Fransche Guadeloupe. De franc was verdeeld in 20 sous. Normaal was I Rijksdaalder = I Spaansche dollar (of mat) (de pilaardaalder $)=$ I Amerikaansche dollar, gelijk aan Io8 sous, terwij1 in de kleinhandel I sou gelijk was aan $2 \frac{1}{2}$ cent en aan I dollarcent.

Door de enorme daling van de franc was deze verhouding natuurlijk verstoord. De winkeliers hielden echter de menschen zooveel mogelijk in onwetendheid en profiteerden voortdurend van de dalingen, waar deze niet aan het publiek bekend werden gemaakt. Als een arbeider, met het in den vreemde verdiende Amerikaansche geld en de ambtenaar, die zijn tractement in Curaçaosch geld kreeg, in de winkels kwamen betalen, werden zij gedwongen bij de terugbetaling gedeprecieerd fransch geld voor nominaal of bijna nominaal in ontvangst te nemen, terwij1 bij de berekening van de prijzen der artikelen de handelaar natuurlijk met de lage waarde van de franc rekening hield. De wet van Gresham toonde zich in al haar macht: de sterkere muntsoort werd verdrongen door de zwakkere. Het land werd overstroomd met Fransch geld en de Curaçaosche (Hollandsche) gulden en de Amerikaansche dollar verdwenen in de lade van den winkeliar om alleen bij het overmaken van geld naar den vreemde natuurlijk te voorschijn te komen.

In dezen toestand is thans eenige verbetering gekomen. De Gezaghebber ontvangt geregeld de koersen van Sint Kitts en makkt deze algemeen bekend, zoodat ook de arbeider de werkelijke waarde van de franc te weten krijgt. Door maximumprijzen vast te stellen voor de voornaamste levensmiddelen en deze prijzen vast te leggen in sous en Curaçaosch geld en algemeen te publiceeren, worden de arbeider en de ambtenaar eveneens gesteund tegen den woeker van enkele winkeliers. Komt straks eene betere verbinding tusschen de omliggende eilanden tot stand, dan zal zeker de winkelier gedwongen worden met een kleinere winst genoegen te nemen, anders worden alle inkoopen in Sint Kitts gedaan.

Alvorens mijne beschouwingen over Sint Martin te eindigen, wil ik nog twee punten aanstippen.

Het eerste punt betreft een vergelijking met Marigot en het Fransche gedeelte van Sint Martin.

De indruk, dien ik van Marigot bij mijn kort bezoek kreeg was in het algemeen nog slechter dan die van Philipsburg. Ook 


$$
406
$$

dáár alles vervallen, de haven geheel verlaten, slechte wegen, enz. Men betaalt in het Fransch gedeelte geen invoerrechten maar alleen een grondbelasting; evenwel wordt er weinig voor de bevolking gedaan, geen scholen van wege het Gouvernement, geen Gouvernements geneeskundige, enz. De klein-landbouw was misschien iets meer ontwikkeld.

Last not least, de „los-van-Curaçao” beweging. Zoowel uit particuliere gesprekken, die ik met verschillende bewoners van Sint Martin had, als uit hetgeen de landraad Waymouth, een der leiders der afscheidingspartij, op de receptie van den Gouverneur tot $\mathrm{ZHEG}$. sprak, meen ik te kunnen concludeeren dat deze beweging geheel geluwd is.

De verschillende voormannen der afscheidingspartij deelden mij mede, dat Sint Martin weinig of geen belangstelling van Curaçao ondervond en dat van hun wenschen weinig of geen notitie genomen werd. Zij beklaagden zich speciaal over het onderwijs; waar de geheele bevolkihg Engelsch spreekt, bleef Nederlandsch de voertaal op school, hetgeen thans met de nieuwe onderwijsverordening gewijzigd wordt. Dan liet de verbinding tusschen de eilanden veel te wenschen over, en kwam hierin weinig verbetering.

Zij beklaagden zich verder, dat de vanuit Curaçao gezonden ambtenaren lang niet altijd van de beste waren en te weinig gecontroleerd werden terwijl zelden hoofdambtenaren het eiland bezochten. De ambtenaren traden vaak despotisch op en klachten te Curaçao hadden weinig succes.

De uitzending van den nieuwen rechter was reeds een groote voldoening voor de bewoners. Toch had de beweging nog aanhang, maar wachtte men met het opzenden der petitie tot de Gouverneur kwam.

Uit de verschillende besprekingen van den Gouverneur en zijn gevolg met de bewoners was het geschokte vertrouwen in Curaçao hersteld en men was overtuigd, dat Sint Martin door Curaçao in de toekomst niet vergeten zou worden.

Moge het draadloos station op Sint Martin spoedig gebouwd worden, en Sint Martin zal met de andere Bovenwindsche eilanden uit hun isolement gehaald worden.

Sint Eustatius.

't Kan verkeeren. Bredero's spreuk is zeker op St. Eustatius 
van toepassing. In den Noord-Amerikaanschen vrijheidsoorlog werd Statia de Golden Rock genoemd. Druk scheepvaartverkeer, handel en welvaart op het geheele eiland. En thans ! De Golden Rock is verdwenen alleen de Rock is er nog en tegen die rots beukt voortdurend de zee en neemt aan het strand de bouwvallen van groote pakhuizen, die aan vroegere grootheid herinneren, weg. De rijke koopliedenfamilies hebben het eiland verlaten en zijn naar Sint Thomas en andere eilanden getrokken, maar de groote ruïnen der Nederlandsch-Hervormde kerk en der Synagoge met de daarom gelegen begraafplaatsen wijzen U, dat de tijd van bloei voorbij is en het nageslacht niet bij machte geweest is, om die oude gedenkteekenen tegen al te groot verval te behoeden.

Het vulkanisch gevormd eiland is thans slechts bewoond door I 400 zielen, die voornamelijk in Oranjestad wonen. Buiten de hoofdplaats wonen zelfs de klein-landbouwers of huurders van grondjes niet. Eien enkele houdt bij den naderenden oogst des nachts op zijn grond in een tijdelijk opgestelde hut de wacht.

De bevolking gaf blijken van haar hartelijkheid in de serenade, die ze op den aankomstavond aan den Gouverneur bracht. Een paar violen, een gitaar en de wiri, (d. i. een stuk koperen pijp met een ruw oppervlak waaruit, door er met een ijzeren spijker over te strijken, een eentonig geluid wordt voortgebracht) niet te vergeten, was de muziek, waarachter de bevolking aanstroomde. Vóór het Gezaghebbershuis werd eerst het „Wien Neêrlandsch Bloed" gespeeld en daarna medegezongen door het geheele jubelende publiek. Op een aardig Engelsch deuntje het volgend liedje :

„Our Governor is present, how happy are we,
We will go forth to meet him and welcome him too,
And all the best flowers our land can produce,
We will take to our Governor for his best use.
Our flags will be flying and our music will play,
God bless our Governor the people will say.
Our dresses are white and our ribbons are blue,
We will go forth to meet him and welcome him too".

Zoowel bij deze twee liederen als bij de later ten beste gegeven nummers dansten twee kinderen negerdansen.

De grond is over het algemeen vruchtbaar en door de grootere 
regenval is de katoencultuur iets minder riskant dan op Sint Martin, maar blijft toch een cultuur met vele misoogsten.

Het Gouvernement bezit uitgestrekte terreinen op Sint Eustatius, n.1. de plantages Zeelandia (Bottom Concordia), Little Mountains (Kleine bergen), Bengalen, Tumble Down Dick (Anna's Lust) en een groot stuk Back of the Mountain (Compagnie's land).

Het grootste gedeelte is voor den klein-landbouw uitgegeven in stukken van 0.5 H.A. tot 8 H.A. toe.

Het Gouvernement plantte in haar proeftuin zelf katoen en deze katoen werd evenals de door den klein-landbouw verbouwde in het Katoenhuis ,,gegind”. Het Katoenhuis werd in Igo8 door den Gezaghebber Van Grol van Gouvernementswege opgericht en de katoen werd daar door twee ,cotton-gins” (van het Eng. „engine” = machine) ontzaad voor den kostenden prijs.

Op de te velde staande katoen worden door het Gouvernement voorschotten verleend en de katoen wordt van wege het Gouvernement op de Engelsche markt verkocht, terwij1 het zaad naar Barbados wordt gezonden, waar de Barbados Coöperative Cotton Factory Co. het zaad perst ter vervaardiging van de katoenzaadolie.

Het Bestuur heeft bij het verhuren van Gouvernementsgronden aan den kleinen landbouw de hand aan het innen der huren niet gehouden, met het gevolg dat het grootste deel der huren in de laatste 5 jaar niet betaald is en de Statiaan niet doordrongen is van de waarde van den grond. De Gouvernementsgronden werden daarbij nog in strijd met het huurcontract dikwijls door den huurder weder onderverhuurd, speciaal aan bewoners van Sint Barths en Sint Kitts, en de onderhtuurder betaalde den huurder wèl, maar deze het Gouvernement niet. Op Gouvernementsgrond werd tevens roofbouw uitgeoefend en wanneer de grond uitgeput raakte, werd hij verlaten en dan was dit verlaten een goede aanleiding om de huur van de afgeloopen jaren niet te betalen. De landbouwers wonen in den regel in Oranjestad en niet bij hun land, zooals reeds boven is gezegd, hetgeen tot gevolg geeft dat er geen toezicht op de cultuur is en dikwijls de te velde staande oogst gestolen wordt. De Statiaan plant dan ook alleen als hij weet, dat iedereen plant, anders is hij zeker, dat hij zelf niet oogsten zal, wat hij gezaaid heeft. Voegt men hierbij nog het feit, dat voortdurend de inwon 
wegtrekken om speciaal in New York als havenarbeider den kost te verdienen, dan kan men omtrent den toestand van Sint Eustatius niet te pessimistisch wezen. Er is echter een lichtpunt: „De Cultuur maatschappij der Nederlandsche Antillen”, opgericht in I9I4 door J. H. J. Hamelberg, den bekenden schrijver van de verschillende geschiedkundige en geografische studies over de Kolonie Curaçao, heeft op St. Eustatius haar sisalcultuur. Onder leiding van den administrateur, den heer Wilde, is een oppervlakte van ruim 400 acres, welke bijna woest was, in een prachtige cultuurvlakte met flinke wegen herschapen. Het hoofdgewas der maatschappij is de sisal, die op Sint Eustatius prachtig groeit. In de fabriek, onder uitsluitende leiding vzn den heer Wilde gebouwd, worden sisalbladeren tot vezel verwerkt en verder gedroogd en tot balen gereed gemaakt voor verzending naar Holland. Van de afvalsisal wordt touw geslagen. De cassave wordt evenals de yams voor volksvoedsel geplant. Het eerste gewas levert behalve de farine, een soort havermout, stijfsel op, welke op Curaçao en omliggende eilanden met succes verkocht wordt.

De katoen wordt tusschen jonge sisal geplant en in een eigen "gin" ontpit. De groote verdienste van de Maatschappij en speciaal van haar administrateur is, dat niet alleen voortdurend onder deskundige leiding de arbeider den veldarbeid leert, maar dat uit groen materiaal timmerlieden, smids, metselaars, bankwerkers, enz. zijn gekweekt.

De bewering wordt wel geuit dat deze Cultuur Maatschappij de landarbeiders uit St. Eustatius van de andere plantages weggetrokken heeft.

De volgende staat, mij verstrekt door den heer Wilde, weerlegt duidelijk deze bewering:

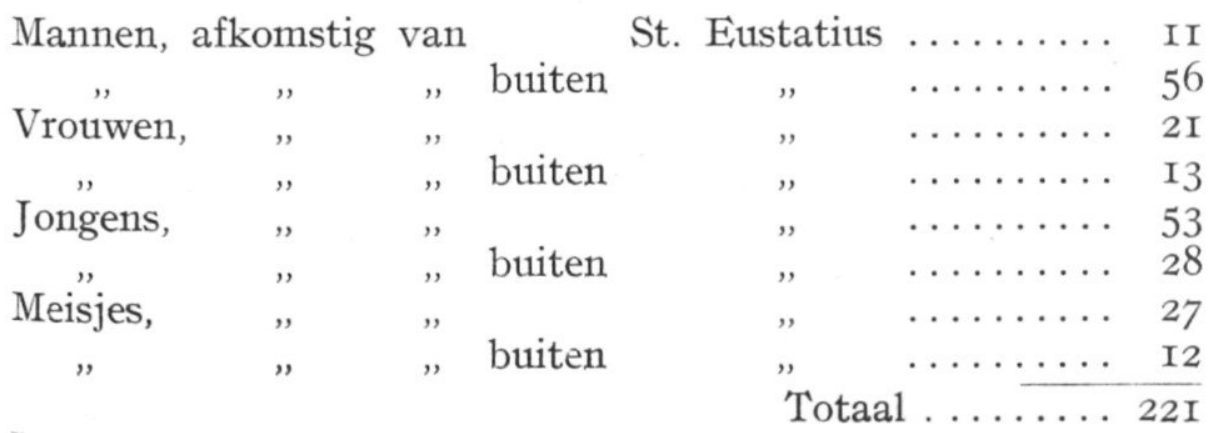


Behalve de bovengenoemde personen vonden nog 8 inboorlingen van Sint Eustatius, die zelf kleine planters zijn, geregeld werk bij de maatschappij gedurende de laatste zware droogte.

Moge de „Cultuur Maatschappij der Nederlandsche Antillen" waarin het Gouvernement voor een belangrijk bedrag aandeelhouder is, in voorspoed tot heil van Sint Eustatius toenemen, en dit eiland op die manier uit zijn verval opgeheven worden.

Wat het muntwezen op Sint Eustatius betreft zij opgemerkt dat daar Hollandsch en Engelsch geld in omloop is. Het Engelsche geld komt veel in van het naburige St. Kitts. De shilling is er equivalent aan 60 cent Curaçaosch courant en gelijk aan 24 cent Amerikaansch courant, terwijl de St. Kitts'papieren dollar geldt voor gelijkwaardig met de Amerikaansche dollar en de Rijksdaalder.

\section{Saba.}

Wanneer het U gelukt is met het roeibootje droog aan wal te komen en ge den moeilijk begaanbaren weg, grootendeels uit trappen bestaande, naar boven bent geklommen, dan komt ge eindelijk in een heerlijke vallei, waarin alleraardigste huisjes staan, netjes geschilderd, en ge bent in Saba's hoofddorpje, "The Bottom" genaamd aangekomen. Wat maakt alles een prettigen indruk op $U$. Ge voelt $U$ als in een andere wereld, die heerlijke bergtoppen om $U$ heen en dan die kleurrijke huisjes.

Onwillekeurig vraagt men zich af of men wel op een der Nederlandsch West-Indische eilanden is, of in een of ander heerlijk bergland van Midden Europa. En wanneer men dan den volgenden dag, hetzij te voet, hetzij te paard naar Windwardside en Hell's Gate gaat, dan geniet men van de schoonste natuurtafereelen en van de mooie huisjes, die Windwardside heeft en men krijgt een rustig gevoel over zich. Zoo nu en dan wordt men in zijne mijmeringen gestoord doordat de weg wel wat al te moeilijk en gevaarlijk is, maar het Sabaansche paard is voorzichtig en men gaat kalm zijns weegs. In de dorpen, zoowel The Bottom, als Windwardside en Hell's Gate ziet men overal vrouwen en kinderen met borduur- en kantwerk bezig en ze loopen uit om het te verkoopen.

De bewoners van Saba zijn ijverig en alles maakt een even prettigen indruk. Te midden van de rotsen ziet men de aard- 
appelen en andere gewassen staan en men verwondert zich vaak hoe op een dergelijke helling de arbeider kan komen om zijn grondje te beplanten, want er zijn weinig stukken grond, die vlak zijn. Voor het bouwen van een regenbak te Hell's Gate kon het Gouvernement geen vlak stuk grond van $\mathrm{I}_{5} \times \mathrm{I}_{5}$ meter krijgen!

De bewoners van het eiland, die voor het meerendeel nog uit blanken bestaan, verdienen grootendeels hun geld met varen, speciaal in Amerikaanschen dienst. Hoewel een enkele wegtrekt komt toch het meerendeel geregeld op het eiland terug en zoekt de zeeman op Saba weer zijn vrouw, die daar blijft wonen. 't Is jammer dat dit wegtrekken toeneemt en de vrouwen ook naar Amerika worden geroepen.

Amerikaansch geld is over het algemeen op Saba in omloop en werd vóór kort nog voor I Amerikaansche dollar I Rijksdaalder in ontvangst genomen. In verband met de hooge dollarkoers in Sint Kitts geldt zij thans voor $\mathrm{f} 2.60$.

De cursus voor zeevaartkunde heeft op Saba succes. De Sabanen, die deze met goed gevolg doorloopen hebben, worden al gauw in Amerika stuurman. Wellicht verdient het aanbeveling dat dit onderwijs nog uitgebreid en verbeterd wordt.

Natuurlijk verlieten we Saba niet alvorens een bezoek gebracht te hebben aan Mary Point. Dit gehuchtje ligt vijf kwartier loopens van The Bottom en de weg, voortdurend op en afgaand, is zeer moeilijk begaanbaar en een paard, zelfs een mak Sabaansch paard, kan U er onmogelijk brengen. Het is wel begrijpelijk dat Mary Point zelden bezocht wordt en de I4 gezinnen leiden dan ook een plantenleven en zelfs de Gouvernements geneeskundige komt er zelden of nooit hulp verschaffen; alleen de pastoor komt er elke week.

Aan dit isolement zou, bij een kleine verbetering aan den weg, waardoor deze ten minste gedeeltelijk te paard berijdbaar zal zijn, een verandering kunnen worden gebracht, want deze menschen mogen die medische hulp niet ontberen. Wat een armoede onder die blanken, die er bijna allemaal even zwak uitzagen !

De gezinnen leven van hetgeen hun klein landje hun oplevert; vleesch hebben zij zelden, melk in het geheel niet. Een enkele maal gaat een der bewoners beneden aan de baai visch voor de bewoners vangen. De stakkers moeten geholpen worden aan een melkkoe, teneinde zwakken en zieken van melk ta voorzien. Dit zijn minimum-eischen. 
Het beste zou zijn deze menschen over te brengen naar The Bottom, maar dit wenschen zij niet en zij willen blijven op hun klein stuk grond nijver landbouwend en handwerkend.

Een groote verbetering is de school, die met Gouvernementssteun door den heer Skerritt, afkomstig van St. Kitts, daar is opgericht. Hij geeft daar les en daarvan wordt ruim gebruik gemaakt, zoowel door jong als oud. Al is het lokaal primitief, eigenlijk maar een kamertje, toch is het zeker al een heele aanwinst.

Ten slotte nog de volgende opmerkingen.

De Bovenwindsche eilanden zijn in vergelijking met de eilanden in onze Oost zeer klein en haar huishouding is, doordat de eilanden zoo ver van elkaar liggen, betrekkelijk kostbaar en hieraan is weinig te doen.

De uitgaven voor die eilanden zullen toenemen en men behoeft daarbij geen grootsche plannen voor oogen te hebben. Zij zijn verwaarloosd en ten einde ze eenigszins op te heffen, zullen kosten gemaakt moeten worden, al moet men ten opzichte van de toekomst van deze eilanden niet optimistisch wezen : aan het wegtrekken van de arbeidskrachten valt vrijwel niets te doen. Toch heeft Nederland ook hier een taak te vervullen; jammer dat het vaak zoo weinig van zijn belangstelling doet blijken. Het oorlogschip was met 24 officieren en 220 man om den Gouverneur en gezelschap naar de eilanden te brengen. Nergens gingen de officieren en manschappen aan wal tot groote teleurstelling der bevolking, die geheel op hun ,man-of-war” gerekend had. De Zeeland liet Gouverneur en gezelschap landen en trok zelf op bezoek naar vreemde koloniën en liet de schoone gelegenheid om de Nederlandsche bezittingen in onze West aan Nederlanders bekend te maken ongebruikt voorbij gaan.

In dit opzicht heeft Nederland zijn plicht verzaakt. Moge deze fout een volgende keer hersteld worden en de Bovenwinders duidelijk merken, dat Nederland belang stelt in hun leven en werken. 